SILVA, Lucas Antônio Lopes da; TEIXEIRA, Paulo Enderson de Oliveira; MENDES, Renat Nureyev. Por uma diferenciação dos critérios de justiça, validade e eficácia das normas jurídicas: Leitura comparativa das obras Teoria Pura do Direito, de Hans Kelsen e Teoria da Norma Jurídica, de Norberto Bobbio. Revista Eletrônica Direito e Política, Programa de Pós-Graduação Stricto Sensu em Ciência Jurídica da UNIVALI, Itajaí, v.11, n.2, 20 quadrimestre de 2016. Disponível em: www.univali.br/direitoepolitica - ISSN 1980-7791.

\title{
POR UMA DIFERENCIAÇÃO DOS CRITÉRIOS DE JUSTIÇA, VALIDADE E EFICÁCIA DAS NORMAS JURÍDICAS: LEITURA COMPARATIVA DAS OBRAS TEORIA PURA DO DIREITO, DE HANS KELSEN, E TEORIA DA NORMA JURÍDICA, DE NORBERTO BOBBIO
}

\author{
BY DIFFERENTIATING CRITERIA OF JUSTICE, VALIDITY AND \\ EFFECTIVENESS OF JURIDICAL NORMA: COMPARATIVE READING OF THE \\ WORKS PURE THEORY OF LAW, HANS KELSEN, AND THEORY OF RULE OF \\ $\angle A W, N O B E R T O B O B B I O$
}

Lucas Antônio Lopes da Silva ${ }^{1}$

Paulo Enderson de Oliveira Teixeira²

Renat Nureyev Mendes ${ }^{3}$

SUMÁRIO: Introdução; 1 Os critérios de Justiça, Validade e Eficácia da Norma Jurídica no Pensamento de Norberto Bobbio; 1.1 Justiça; 1.2 Validade; 1.3 Eficácia; $1.4 \mathrm{~A}$ independência e a confusão dos três critérios; 2 Os critérios de Justiça, Validade e Eficácia da Norma Jurídica no Pensamento de Hans Kelsen;

\footnotetext{
${ }^{1}$ Graduando em Direito pela Faculdade de Ciências Jurídicas de Diamantina, da Universidade do Estado de Minas Gerais (UEMG). Estudante-membro do Grupo de Estudos "Kelsen e Bobbio: por uma diferenciação dos critérios de Justiça, Validade e Eficácia das Normas Jurídicas", desenvolvido na UEMG (Unidade Diamantina), sob orientação do Professor Ms. Paulo Teixeira (E-mail: lucasantoniolopes.s@gmail.com).

2 Graduado em Direito pela Faculdade Mineira de Direito, da Pontifícia Universidade Católica de Minas Gerais. Especialista em Filosofia do Direito (PUC-MG). Mestre e Doutorando em Teoria do Direito, também pela PUC-MG. Professor da PUC-Minas, Campus Serro; e da UEMG, Unidade Diamantina. Mentor e orientador do Grupo de Estudos "Kelsen e Bobbio: por uma diferenciação dos critérios de Justiça, Validade e Eficácia das Normas Jurídicas", desenvolvido na UEMG (Unidade Diamantina) - (E-mail: paulo.oliveirateixeira@yahoo.com.br).

3 Graduado em História pela Universidade Estadual de Montes Claros. Especialista em Didática e Metodologia do Ensino Superior também pela Unimontes. Graduando em Direito pela Faculdade de Ciências Jurídicas de Diamantina, da Universidade do Estado de Minas Gerais. Estudantemembro do Grupo de Estudos "Kelsen e Bobbio: por uma diferenciação dos critérios de Justiça, Validade e Eficácia das Normas Jurídicas", desenvolvido na UEMG (Unidade Diamantina), sob orientação do Professor Ms. Paulo Teixeira - (E-mail: renatnureyev@yahoo.com.br).
} 
SILVA, Lucas Antônio Lopes da; TEIXEIRA, Paulo Enderson de Oliveira; MENDES, Renat Nureyev. Por uma diferenciação dos critérios de justiça, validade e eficácia das normas jurídicas: Leitura comparativa das obras Teoria Pura do Direito, de Hans Kelsen e Teoria da Norma Jurídica, de Norberto Bobbio. Revista Eletrônica Direito e Política, Programa de Pós-Graduação Stricto Sensu em Ciência Jurídica da UNIVALI, Itajaí, v.11, n.2, 20 quadrimestre de 2016. Disponível em: www.univali.br/direitoepolitica - ISSN 1980-7791.

2.1 Justiça; 2.2 Validade e Eficácia; 2.3 Equívocos entre os critérios da Validade e da Eficácia; Considerações finais; Referências das fontes citadas.

\section{RESUMO}

O presente trabalho tem como objetivo a compreensão da leitura dos critérios de Justiça, Validade e Eficácia em Norberto Bobbio e Hans Kelsen. Mesmo ambos sendo adeptos do Juspositivismo, têm compreensões diversas dos critérios já enunciados, e isto (essa diferença dos dois pensadores no interpretar da Teoria do Direito) é que o trabalho se concentrará a buscar ao longo do seu desenvolvimento. Assim, este artigo, baseado na pesquisa bibliográfica e no método comparativo, trará, em um primeiro momento, a leitura dos critérios acima destacados por Bobbio para, a posteriori, fazer o mesmo com o outro autor, com nome Hans Kelsen. Em um último momento, já traçando algumas considerações à guisa de conclusão, tentar-se-á relacionar os pensamentos dos dois autores escolhidos.

PALAVRAS-CHAVE: Justiça; Validade; Eficácia; Bobbio; Kelsen.

\section{ABSTRACT}

This study aims to reading comprehension of Justice criteria, validity and effectiveness on Norberto Bobbio and Hans Kelsen. Even if both are supporters of Juspositivismo have different understandings of the already criteria, and this (the difference of the two thinkers in interpreting the legal theory) is that the work will focus to look over your body text. Thus, this article, based on the literature and the comparative method, will, at first, reading the above criteria highlighted by Bobbio for a posteriori do the same with the other author named Hans Kelsen. In a last moment, already drawing some considerations to a conclusion, it will be tried to relate the thoughts of two chosen authors.

KEYWORDS: Justice; Validity; Effectiveness; Bobbio; Kelsen.

\section{INTRODUÇÃo}

Inicia-se este artigo chamando a atenção do leitor ao fato de não se ter pretensão de esgotar todos os assuntos referentes aos critérios de Justiça, Validade e Eficácia das Normas Jurídicas, doravante apresentados.

A pretensão é bem mais modesta. O objetivo será atendido se, ao fim, for possível compreender como são lidos os critérios supracitados pelos dois autores abordados, quais sejam, Norberto Bobbio e Hans Kelsen. 
SILVA, Lucas Antônio Lopes da; TEIXEIRA, Paulo Enderson de Oliveira; MENDES, Renat Nureyev. Por uma diferenciação dos critérios de justiça, validade e eficácia das normas jurídicas: Leitura comparativa das obras Teoria Pura do Direito, de Hans Kelsen e Teoria da Norma Jurídica, de Norberto Bobbio. Revista Eletrônica Direito e Política, Programa de Pós-Graduação Stricto Sensu em Ciência Jurídica da UNIVALI, Itajaí, v.11, n.2, 20 quadrimestre de 2016. Disponível em: www.univali.br/direitoepolitica - ISSN 1980-7791.

Insta constar que ambos são juspositivistas ${ }^{4}$, no entanto, fazem leituras diversas acerca dos três critérios abordados aqui, neste trabalho. Será essa diferença no estudo dos critérios em comento na obra desses autores é que norteará a escrita deste artigo.

Uma frase de Bobbio condensa toda a justificativa deste trabalho: "a nossa vida se desenvolve em um mundo de normas" ${ }^{\prime \prime}$. Se as normas estão tão presentes na vida dos indivíduos, mister se faz compreendê-las melhor. E será isso o que se procura aqui, a partir da análise dos escritos dos dois jusfilósofos já destacados.

Para tanto, utilizar-se-á, aqui, a pesquisa bibliográfica, atentando-se às principais obras escritas por Bobbio e Kelsen, especialmente a Teoria da Norma Jurídica, do primeiro, e a Teoria Pura do Direito, do último, além de outros trabalhos acadêmicos que tratam do assunto. O método comparativo, nesse sentido, também será de grande valia neste estudo, pois contribuirá para conseguirmos fazer um paralelo entre os pensamentos dos dois autores, objetivo geral deste trabalho.

Optou-se, no que diz respeito à exoestrutura desta monografia, em iniciá-la discorrendo acerca do pensamento de Bobbio, mesmo este vindo cronologicamente depois de Kelsen. Essa escolha se fundamenta na existência do capítulo segundo do livro Teoria da Norma Jurídica, daquele autor, intitulado de "Justiça, Validade e Eficácia". Como Bobbio já bem define os critérios no texto citado, interessante seria partir dessa leitura, já delimitada pelo capítulo em pauta, para, depois, buscar - na obra kelseniana - os mesmos critérios que, como se poderá ver, mesmo estribado na mesma filosofia do juspositivismo, diferenciar-se-á do que é pregado por Bobbio, em alguns aspectos. Em um

\footnotetext{
4 "O positivismo jurídico é uma doutrina do direito que considera que somente é direito aquilo que é posto pelo Estado. Surge para repelir, no jusnaturalismo, tudo aquilo que ultrapasse os limites do que não fora posto e aprovado pelo Estado, revestindo este de único criador do Direito" (BOBBIO apud QUEIRÓZ, 2011, p. 41). "Pode-se dizer que o juspositivismo representa, no ápice da modernidade, uma tentativa de trazer maior rigor e exatidão para seus postulados, como que em uma exatidão matemática, adequando-se o fato concreto à norma hipotética" (QUEIROZ, 2011, p. 41).

${ }^{5}$ BOBBIO, Norberto. Teoria da Norma Jurídica. Bauru (SP): EDIPRO, 2001, p. 23.
} 
SILVA, Lucas Antônio Lopes da; TEIXEIRA, Paulo Enderson de Oliveira; MENDES, Renat Nureyev. Por uma diferenciação dos critérios de justiça, validade e eficácia das normas jurídicas: Leitura comparativa das obras Teoria Pura do Direito, de Hans Kelsen e Teoria da Norma Jurídica, de Norberto Bobbio. Revista Eletrônica Direito e Política, Programa de Pós-Graduação Stricto Sensu em Ciência Jurídica da UNIVALI, Itajaí, v.11, n.2, $2^{\circ}$ quadrimestre de 2016. Disponível em: www.univali.br/direitoepolitica - ISSN 1980-7791.

último momento, já traçando algumas considerações à guisa de conclusão, tentar-se-á relacionar os pensamentos dos dois autores escolhidos.

\section{OS CRITÉRIOS DE JUSTIÇA, VALIDADE E EFICÁCIA DA NORMA JURÍDICA NO PENSAMENTO DE NORBERTO BOBBIO}

Norberto Bobbio nasceu em Turim, no norte da Itália, em 18 de outubro de 1909. Ele é um dos mais ilustres jusfilósofos do século XX. Estudou Direito e Filosofia na Universidade de Turim. Doutorou-se também em Turim. Obteve, a posteriori, a livre docência em Filosofia do Direito. Foi Professor de Filosofia do Direito em Camerino (1936-1938), em Siena (1938-1940), em Pádua (19401948) e, de 1948 a 1972, lecionou na Faculdade de Direito da Universidade de Turim. De 1973 a 1984, lecionou Filosofia Política na Faculdade de Ciências Políticas da mesma Universidade, sendo também senador vitalício. Ele faleceu em 9 de janeiro de 2004, aos 94 anos.

Bobbio - que era um exímio defensor do Juspositivismo - deixou uma vasta produção acadêmica, com escritos concisos, lógicos e, ainda assim, densos. Dentre a sua produção, destaca-se, aqui (por sua pertinência), a obra Teoria da Norma Jurídica, que, em seu capítulo II, traz à baila alguns comentários sobre os critérios da "Justiça, Validade e Eficácia" da Norma Jurídica.

Segundo Bobbio6, para se estabelecer uma Teoria da Norma Jurídica, com fundamentos sólidos, faz-se imprescindível que esta seja submetida a três valorações distintas e independentes uma das outras, a saber: a) se é justa ou injusta; b) se é válida ou inválida; c) se é eficaz ou ineficaz.

\subsection{JUSTIÇA}

${ }^{6}$ BOBBIO, Norberto. Teoria da Norma Jurídica. Bauru (SP): EDIPRO, 2001. 
SILVA, Lucas Antônio Lopes da; TEIXEIRA, Paulo Enderson de Oliveira; MENDES, Renat Nureyev. Por uma diferenciação dos critérios de justiça, validade e eficácia das normas jurídicas: Leitura comparativa das obras Teoria Pura do Direito, de Hans Kelsen e Teoria da Norma Jurídica, de Norberto Bobbio. Revista Eletrônica Direito e Política, Programa de Pós-Graduação Stricto Sensu em Ciência Jurídica da UNIVALI, Itajaí, v.11, n.2, 20 quadrimestre de 2016. Disponível em: www.univali.br/direitoepolitica - ISSN 1980-7791.

O problema da justiça "é o problema da correspondência ou não da norma aos valores últimos ou finais que inspiram um determinado ordenamento jurídico"7. O autor em comento não toca na questão que busca refletir se existe um ideal de bem comum idêntico para todos os tempos e para todos os lugares. Ele quer tão somente "constatar que todo ordenamento jurídico persegue certos fins, e convir sobre o fato de que estes fins representam os valores a cuja realização o legislador, mais ou menos conscientemente, mais ou menos adequadamente, dirige sua própria obra"8.

Considerando a existência desses valores supremos, "objetivamente evidentes, a pergunta se uma norma é justa ou injusta equivale a perguntar se é apta ou não a realizar esses valores" ${ }^{\prime \prime}$. Entretanto, no caso de desconsideração destes valores absolutos, "é concernente perguntar se a norma é apta ou não a realizar valores históricos que inspiram um ordenamento [jurídico] concreto e historicamente determinado"10.

O saber se uma norma jurídica é justa ou injusta é um aspecto contrastante entre o mundo ideal e o mundo real, entre o que deve ser e o que é. Dito de uma outra forma, "o problema da justiça, então, se refere à dicotomia entre o mundo ideal e o mundo real, ou seja, entre o que deve ser e o que de fato é: norma justa seria aquela que deve ser; e injusta aquela que não deveria ser" ${ }^{\prime 11}$, 0 que diagnostica o problema da justiça como um problema deontológico do Direito.

\footnotetext{
7 BOBBIO, Norberto. Teoria da Norma Jurídica. Bauru (SP): EDIPRO, 2001, p. 46.

8 BOBBIO, Norberto. Teoria da Norma Jurídica. Bauru (SP): EDIPRO, 2001, p. 46.

9 BOBBIO, Norberto. Teoria da Norma Jurídica. Bauru (SP): EDIPRO, 2001, p. 46.

10 PETRUCELI, Isabel Helena Andrade. Justiça, Validade e Eficácia das Normas Jurídicas - uma comparação entre a Teoria da Norma Jurídica de Norberto Bobbio e a Teoria Pura do Direito de Hans Kelsen. Revista E-Civitas, Uni-BH, Belo Horizonte, v. 1, n. 1, 2008.

11 PETRUCELI, Isabel Helena Andrade. Justiça, Validade e Eficácia das Normas Jurídicas - uma comparação entre a Teoria da Norma Jurídica de Norberto Bobbio e a Teoria Pura do Direito de Hans Kelsen. Revista E-Civitas, Uni-BH, Belo Horizonte, v. 1, n. 1, 2008.
} 
SILVA, Lucas Antônio Lopes da; TEIXEIRA, Paulo Enderson de Oliveira; MENDES, Renat Nureyev. Por uma diferenciação dos critérios de justiça, validade e eficácia das normas jurídicas: Leitura comparativa das obras Teoria Pura do Direito, de Hans Kelsen e Teoria da Norma Jurídica, de Norberto Bobbio. Revista Eletrônica Direito e Política, Programa de Pós-Graduação Stricto Sensu em Ciência Jurídica da UNIVALI, Itajaí, v.11, n.2, 20 quadrimestre de 2016. Disponível em: www.univali.br/direitoepolitica - ISSN 1980-7791.

Logo, sobre a questão da justiça da norma jurídica, "é necessário examinar a aptidão para o ideal do bem comum e entre o dever ser, que significa a norma justa, e o não dever ser, que reflete a norma injusta"12.

\subsection{VALIDADE}

A validade relaciona-se à estrita observância técnica, "não se ajuíza de um ponto de vista axio-valorativo, mas sim técnico-jurídico"13. Portanto,

Saber se uma norma é válida é saber se esta faz parte do ordenamento jurídico, desta forma três análises podem ser feitas: indagar da autoridade do órgão que a emanou; saber da sua possível ab-rogação, direta ou implícita. Tratamos aqui da problemática 'ontológica do direito' ${ }^{14}$.

Com efeito, há de se constatar se uma regra jurídica existe ou não, já que a "validade relaciona-se diretamente com a existência da regra enquanto tal, independentemente do juízo de valor sobre ela ser justo ou não"15. Em resumo, a validade jurídica de uma norma equivale à existência dessa norma como regra jurídica.

Como já demonstrado em uma citação acima, para se decidir se uma norma é válida é necessário fazer três averiguações:

\section{I) Se a autoridade de quem ela originou-se tinha poder legítimo para} emanar normas jurídicas: esta investigação conduz até a Norma Fundamental, termo (e conceito) kelseniano, que Bobbio explica no seu livro Teoria do Ordenamento jurídico: "a norma fundamental é o critério supremo que permite

12 BAGGENSTOSS, Grazielly Alessandra. A contemporaneidade das teorias reducionistas a partir da teoria jurídica bobbiana. Revista de Estudos Constitucionais, Hermenêutica e Teoria do Direito (RECHTD), v. 6, n. 2, julho-setembro, 2014, p. 168.

13 LOURINHO, Sergio Manuel. Norberto Bobbio e uma Teoria Geral do Direito. Revista Jurídica das Faculdades Secal, Ponta Grossa, v. 1, n. 1, jan./jun., 2011, p. 104.

14 LOURINHO, Sergio Manuel. Norberto Bobbio e uma Teoria Geral do Direito. Revista Jurídica das Faculdades Secal, Ponta Grossa, v. 1, n. 1, jan./jun., 2011, p. 104.

15 PETRUCELI, Isabel Helena Andrade. Justiça, Validade e Eficácia das Normas Jurídicas - uma comparação entre a Teoria da Norma Jurídica de Norberto Bobbio e a Teoria Pura do Direito de Hans Kelsen. Revista E-Civitas, Uni-BH, Belo Horizonte, v. 1, n. 1, 2008. 
SILVA, Lucas Antônio Lopes da; TEIXEIRA, Paulo Enderson de Oliveira; MENDES, Renat Nureyev. Por uma diferenciação dos critérios de justiça, validade e eficácia das normas jurídicas: Leitura comparativa das obras Teoria Pura do Direito, de Hans Kelsen e Teoria da Norma Jurídica, de Norberto Bobbio. Revista Eletrônica Direito e Política, Programa de Pós-Graduação Stricto Sensu em Ciência Jurídica da UNIVALI, Itajaí, v.11, n.2, $2^{\circ}$ quadrimestre de 2016. Disponível em: www.univali.br/direitoepolitica - ISSN 1980-7791.

estabelecer se uma norma pertence a um ordenamento; em outras palavras, é o fundamento de validade de todas as normas do sistema"16.

II) Se foi ab-rogada: não obstante tenha sido emanada de um comando autorizado, pode ter sido ab-rogada por uma outra norma jurídica que a tenha expressamente sucedido no tempo, ou tenha regulado, de maneira diferente, a mesma matéria.

III) Se não é incompatível com outras normas do Sistema: Também chamada de "ab-rogação implícita". Tem-se, nesta hipótese, que averiguar se não há uma incompatibilidade com uma norma hierarquicamente superior (a Constituição seria o melhor dos exemplos), ou, outrossim, com norma posterior. Em ambos os casos, ter-se-ia a invalidade (automática) da norma jurídica analisada.

\subsection{EFICÁCIA}

O Direito Positivo "não é elaborado para permanecer guardado, sob a forma de texto, nos códigos e nas leis, mas destina-se à concreção na realidade social, à aplicação no tempo e no espaço"17. Não basta, por isso, "que a lei seja vigente; é preciso que ela seja, também, eficaz, ou seja, que cumpra a finalidade a que foi predestinada"18.

A eficácia diz respeito "à norma na sua relação com os destinatários da mesma, a questão que se coloca é saber se uma determinada norma é ou não seguida e as razões advenientes, no caso de resposta negativa, é aqui colocado o 'problema fenomenológico do direito'"19. Em síntese, a eficácia "está relacionada

\footnotetext{
16 BOBBIO, Norberto. Teoria do Ordenamento Jurídico. Brasília: Editora UnB, 1999.

17 MENDONÇA, Jacy de Souza. Introdução ao Estudo do Direito. 3a. ed. São Paulo: Rideel, 2010, p. 89.

18 MENDONÇA, Jacy de Souza. Introdução ao Estudo do Direito. 3a. ed. São Paulo: Rideel, 2010, p. 89.

19 LOURINHO, Sergio Manuel. Norberto Bobbio e uma Teoria Geral do Direito. Revista Jurídica das Faculdades Secal, Ponta Grossa, v. 1, n. 1, jan./jun., 2011, p. 104.
} 
SILVA, Lucas Antônio Lopes da; TEIXEIRA, Paulo Enderson de Oliveira; MENDES, Renat Nureyev. Por uma diferenciação dos critérios de justiça, validade e eficácia das normas jurídicas: Leitura comparativa das obras Teoria Pura do Direito, de Hans Kelsen e Teoria da Norma Jurídica, de Norberto Bobbio. Revista Eletrônica Direito e Política, Programa de Pós-Graduação Stricto Sensu em Ciência Jurídica da UNIVALI, Itajaí, v.11, n.2, $2^{\circ}$ quadrimestre de 2016. Disponível em: www.univali.br/direitoepolitica - ISSN 1980-7791.

ao problema de uma norma ser ou não seguida pelas pessoas [os chamados destinatários da norma jurídica, no entender de Bobbio ${ }^{20}$ ] a quem ela se dirige, e, no caso de violação, se ela é imposta através de meios coercitivos oferecidos pela autoridade que a evocou"21.

A existência de uma norma jurídica não implica que ela seja também constantemente seguida ${ }^{22}$, daí a independência dos critérios, tão defendida por Bobbio $^{23}$. Ainda sobre a eficácia da norma jurídica, Bobbio leciona:

Não é nossa tarefa aqui indagar quais possam ser as razões para que uma norma seja mais ou menos seguida. Limitamo-nos a constatar que há de existir normas que são seguidas universalmente de modo espontâneo (e são as mais eficazes), outras que são seguidas na generalidade dos casos somente quando estão providas de coação, e outras, enfim, que são violadas sem que nem sequer seja aplicada a coação (e são as mais ineficazes). A investigação para averiguar a eficácia ou a ineficácia de uma norma é de caráter histórico-sociológico, se volta para o estudo do comportamento dos membros de um determinado grupo social e se diferencia, seja da investigação tipicamente filosófica em torno da justiça, seja da tipicamente jurídica em torno da validade. Aqui também, para usar a terminologia douta, se bem que em sentido diverso do habitual, pode se dizer que o problema da eficácia das regras jurídicas é o problema fenomenológico do direito ${ }^{24}$.

\subsection{A INDEPENDÊNCIA E A CONFUSÃO DOS TRÊS CRITÉRIOS}

Como já esclarecido, Justiça, Validade e Eficácia são critérios independentes que dão origens a três ordens distintas de problemas. Logo, a existência de um não

20 BOBBIO, Norberto. Teoria da Norma Jurídica. Bauru (SP): EDIPRO, 2001.

21 PETRUCELI, Isabel Helena Andrade. Justiça, Validade e Eficácia das Normas Jurídicas - uma comparação entre a Teoria da Norma Jurídica de Norberto Bobbio e a Teoria Pura do Direito de Hans Kelsen. Revista E-Civitas, Uni-BH, Belo Horizonte, v. 1, n. 1, 2008.

22 PETRUCELI, Isabel Helena Andrade. Justiça, Validade e Eficácia das Normas Jurídicas - uma comparação entre a Teoria da Norma Jurídica de Norberto Bobbio e a Teoria Pura do Direito de Hans Kelsen. Revista E-Civitas, Uni-BH, Belo Horizonte, v. 1, n. 1, 2008.

23 BOBBIO, Norberto. Teoria da Norma Jurídica. Bauru (SP): EDIPRO, 2001.

${ }^{24}$ BOBBIO, Norberto. Teoria da Norma Jurídica. Bauru (SP): EDIPRO, 2001, pp. 47-48. 
SILVA, Lucas Antônio Lopes da; TEIXEIRA, Paulo Enderson de Oliveira; MENDES, Renat Nureyev. Por uma diferenciação dos critérios de justiça, validade e eficácia das normas jurídicas: Leitura comparativa das obras Teoria Pura do Direito, de Hans Kelsen e Teoria da Norma Jurídica, de Norberto Bobbio. Revista Eletrônica Direito e Política, Programa de Pós-Graduação Stricto Sensu em Ciência Jurídica da UNIVALI, Itajaí, v.11, n.2, $2^{\circ}$ quadrimestre de 2016. Disponível em: www.univali.br/direitoepolitica - ISSN 1980-7791.

pressupõe a existência do outro. Estes três critérios de valoração de uma norma dão origem às seguintes proposições:

I - Uma norma pode ser justa sem ser válida: O exemplo mais ilustrativo dessa possibilidade é o referente ao Jusnaturalismo, já que os teóricos dessa doutrina "formulavam em seus tratados um sistema de normas advindo de princípios jurídicos universais. Quem formulava estas normas, considerava-as justas, porque as inferia de princípios universais de justiça"25. Estas normas formuladas pelos Jusnaturalistas, no entanto, não seriam, pois, válidas, a não ser que escritas em um Tratado de Direito Natural. Tornar-se-iam válidas na justa medida em que fossem acolhidas por um sistema de Direito Positivo. "O direito natural pretende ser o direito justo por excelência, mas somente pelo fato de ser justo não é também válido"26.

II - Uma norma pode ser válida sem ser justa: Nenhum ordenamento jurídico é perfeito: por vezes há uma distância entre o ideal de justiça e a realidade do Direito. "Fatos históricos comprovam esta afirmação; os regimes de escravidão, comuns nas sociedades passadas, postulavam normas que nenhuma pessoa racional [deste tempo] consideraria justa, entretanto, uma vez positivadas, eram válidas"27.

III - Uma norma pode válida sem ser eficaz: "O caso mais clamoroso é sempre o das leis de proibição de bebidas alcoólicas nos Estados Unidos da América, que vigoraram durante vinte anos entre as duas guerras" 28 . Durante esse período, o consumo de bebida alcoólica não foi inferior ao período imediatamente sucessivo, quando a lei seca foi abolida. As leis de proibição de bebidas alcoólicas nos EUA eram, portanto, leis válidas, mas não eficazes.

\footnotetext{
25 BOBBIO, Norberto. Teoria da Norma Jurídica. Bauru (SP): EDIPRO, 2001, p. 48.

${ }^{26}$ BOBBIO, Norberto. Teoria da Norma Jurídica. Bauru (SP): EDIPRO, 2001, p. 48.

27 PETRUCELI, Isabel Helena Andrade. Justiça, Validade e Eficácia das Normas Jurídicas - uma comparação entre a Teoria da Norma Jurídica de Norberto Bobbio e a Teoria Pura do Direito de Hans Kelsen. Revista E-Civitas, Uni-BH, Belo Horizonte, v. 1, n. 1, 2008.
}

${ }^{28}$ BOBBIO, Norberto. Teoria da Norma Jurídica. Bauru (SP): EDIPRO, 2001, p. 49. 
SILVA, Lucas Antônio Lopes da; TEIXEIRA, Paulo Enderson de Oliveira; MENDES, Renat Nureyev. Por uma diferenciação dos critérios de justiça, validade e eficácia das normas jurídicas: Leitura comparativa das obras Teoria Pura do Direito, de Hans Kelsen e Teoria da Norma Jurídica, de Norberto Bobbio. Revista Eletrônica Direito e Política, Programa de Pós-Graduação Stricto Sensu em Ciência Jurídica da UNIVALI, Itajaí, v.11, n.2, $2^{\circ}$ quadrimestre de 2016. Disponível em: www.univali.br/direitoepolitica - ISSN 1980-7791.

IV - Uma norma pode ser eficaz sem ser válida: Há muitas normas sociais que "vão sendo seguidas espontaneamente ou pelo menos habitualmente, isto é, são eficazes [...]. Estas regras, pelo simples fato de serem seguidas, não se tornam por isso regras pertencentes a um sistema jurídico, ou seja, adquirem validade jurídica"29. Como exemplo, tem-se as regras de boa educação, que "são eficazes no sentido de que são aceitas e aplicadas por todos, mas para serem válidas têm de ser incorporadas num sistema de direito objetivo"30.

V - Uma norma pode ser justa sem ser eficaz: "Se a norma pode ser justa sem ser válida, também podemos dizer, a fortiore, que pode ser justa sem ser eficaz"31, tendo em vista, principalmente, a dificuldade de aplicação da justiça. Muitos são aqueles que levantam suas vozes para exaltar a justiça com palavras, mas poucos são os que transformam em ato todo aquele belo discurso.

VI - Uma norma pode ser eficaz sem ser justa: "O fato de uma norma ser universalmente seguida não demonstra sua justiça, assim como também, o fato de não ser absolutamente obedecida não pode ser considerado prova de sua injustiça" ${ }^{32}$. Com efeito, "a justiça é independente da validade, mas também independente da eficácia"33.

A apreciação dessas seis proposições torna mais clara a observância da independência desses critérios. Desta feita,

A sugestão e análise independente visa o afastamento de certas teorizações reducionistas que reconduzem validade à justiça (doutrina do direito natural), ou justiça à validade (positivismo jurídico) ou, por fim, a validade à eficácia

\footnotetext{
29 BOBBIO, Norberto. Teoria da Norma Jurídica. Bauru (SP): EDIPRO, 2001, pp. 49-50.

30 LOURINHO, Sergio Manuel. Norberto Bobbio e uma Teoria Geral do Direito. Revista Jurídica das Faculdades Secal, Ponta Grossa, v. 1, n. 1, jan./jun., 2011, p. 104.

31 LOURINHO, Sergio Manuel. Norberto Bobbio e uma Teoria Geral do Direito. Revista Jurídica das Faculdades Secal, Ponta Grossa, v. 1, n. 1, jan./jun., 2011, p. 105.

32 BOBBIO, Norberto. Teoria da Norma Jurídica. Bauru (SP): EDIPRO, 2001, p. 50.

33 BOBBIO, Norberto. Teoria da Norma Jurídica. Bauru (SP): EDIPRO, 2001, p. 51.
} 
SILVA, Lucas Antônio Lopes da; TEIXEIRA, Paulo Enderson de Oliveira; MENDES, Renat Nureyev. Por uma diferenciação dos critérios de justiça, validade e eficácia das normas jurídicas: Leitura comparativa das obras Teoria Pura do Direito, de Hans Kelsen e Teoria da Norma Jurídica, de Norberto Bobbio. Revista Eletrônica Direito e Política, Programa de Pós-Graduação Stricto Sensu em Ciência Jurídica da UNIVALI, Itajaí, v.11, n.2, $2^{\circ}$ quadrimestre de 2016. Disponível em: www.univali.br/direitoepolitica - ISSN 1980-7791.

(realismo) e que são descaracterizadoras da totalidade dos três elementos constitutivos da 'experiência jurídica'34.

A doutrina do Direito Natural reduz a validade à justiça, quando afirma que uma norma só é válida se é justa, ou seja, faz depender a validade da justiça. Já a concepção positivista reduz a justiça à validade, afirmando que uma norma é justa somente pelo fato de ser válida, isto é, faz depender a justiça da validade. O Realismo jurídico, para completar a tríade, reduz a validade à eficácia, quando tende a afirmar que o direito real não é aquele que se encontra, por assim dizer, "enunciado em uma Constituição, ou em um Código, ou em um corpo de leis, mas é aquele que os homens efetivamente aplicam nas suas relações cotidianas: esta teoria faz depender, em última análise, a validade da eficácia"35.

Bobbio considera que "todas as três concepções estão viciadas pelo erro do 'reducionismo', que leva à eliminação ou, pelo menos, ao ofuscamento de um dos três elementos constitutivos da experiência jurídica e, portanto, a mutilam"36. Para ele, a primeira e a terceira desconsideram a importância do problema da validade; a segunda, do problema da justiça.

Se Bobbio insiste sobre a distinção e independência dos três valores é porque ele julga prejudicial sua confusão e, sobretudo, considera que não pode aceitar outras teorias que não fazem esta distinção claramente, e tendem, ao contrário, a reduzir ora um, ora outro dos três aspectos, aos outros dois, elaborando, como se costuma dizer, através de feio neologismo da linguagem filosófica, um "reducionismo"37.

\section{OS CRITÉRIOS DE JUSTIÇA, VALIDADE E EFICÁCIA DA NORMA JURÍDICA NO PENSAMENTO DE HANS KELSEN}

\footnotetext{
${ }^{34}$ LOURINHO, Sergio Manuel. Norberto Bobbio e uma Teoria Geral do Direito. Revista Jurídica das Faculdades Secal, Ponta Grossa, v. 1, n. 1, jan./jun., 2011, p. 105.

35 BOBBIO, Norberto. Teoria da Norma Jurídica. Bauru (SP): EDIPRO, 2001, p. 54.

36 BOBBIO, Norberto. Teoria da Norma Jurídica. Bauru (SP): EDIPRO, 2001, p. 54.

37 BOBBIO, Norberto. Teoria da Norma Jurídica. Bauru (SP): EDIPRO, 2001.
} 
SILVA, Lucas Antônio Lopes da; TEIXEIRA, Paulo Enderson de Oliveira; MENDES, Renat Nureyev. Por uma diferenciação dos critérios de justiça, validade e eficácia das normas jurídicas: Leitura comparativa das obras Teoria Pura do Direito, de Hans Kelsen e Teoria da Norma Jurídica, de Norberto Bobbio. Revista Eletrônica Direito e Política, Programa de Pós-Graduação Stricto Sensu em Ciência Jurídica da UNIVALI, Itajaí, v.11, n.2, $2^{\circ}$ quadrimestre de 2016. Disponível em: www.univali.br/direitoepolitica - ISSN 1980-7791.

Hans Kelsen, um dos mais importantes e influentes estudiosos da Ciência Jurídica, nasceu na cidade de Praga, em 11 de outubro de 1881. É na Universidade de Viena que Kelsen constrói sua carreira acadêmica, graduando-se (em Direito e Ciência Política), doutorando-se (em Ciências Jurídicas) e tornando-se Livre-docente (em Direito Constitucional e Filosofia do Direito), onde também lecionou disciplinas afins às suas áreas do saber. Em 19 de abril de 1973 Kelsen vem a falecer em Orinda, perto de Berkeley.

Ele é autor de uma vasta produção acadêmica. Seus livros são lidos por todo o mundo, ainda hoje. Dentre eles, destaca-se, aqui, as seguintes obras: Teoria Pura do Direito (principalmente essa), O Problema da Justiça e O que é Justiça?, que serão utilizadas aqui para se buscar os critérios de Justiça, Validade e Eficácia das Normas Jurídicas, como se verá a seguir.

\subsection{JUSTIÇA}

Na segunda edição da obra Teoria Pura do Direito, publicada em 1960, Kelsen incluiu um ensaio sobre o problema da justiça, reconhecendo a importância do problema para a política jurídica. No entanto, ele isolou-o do texto, apresentando-o como apêndice, por entender que o problema da justiça, como problema valorativo, deveria situar-se fora de uma Teoria do Direito, que se limitaria, por sua vez, à analise do Direito Positivo como sendo a realidade jurídica (única) ${ }^{38}$.

Pode-se depreender que a metáfora de separar o ensaio do resto da obra é ilustrativa do pensamento kelseniano, não porque ele defendia uma separação da justiça do Direito, mas porque entendia que aquela não seria uma conditio sine qua non da ordem social ou jurídica de um lugar. Segundo o autor em tela,

\footnotetext{
38 PETRUCELI, Isabel Helena Andrade. Justiça, Validade e Eficácia das Normas Jurídicas - uma comparação entre a Teoria da Norma Jurídica de Norberto Bobbio e a Teoria Pura do Direito de Hans Kelsen. Revista E-Civitas, Uni-BH, Belo Horizonte, v. 1, n. 1, 2008.
} 
SILVA, Lucas Antônio Lopes da; TEIXEIRA, Paulo Enderson de Oliveira; MENDES, Renat Nureyev. Por uma diferenciação dos critérios de justiça, validade e eficácia das normas jurídicas: Leitura comparativa das obras Teoria Pura do Direito, de Hans Kelsen e Teoria da Norma Jurídica, de Norberto Bobbio. Revista Eletrônica Direito e Política, Programa de Pós-Graduação Stricto Sensu em Ciência Jurídica da UNIVALI, Itajaí, v.11, n.2, 20 quadrimestre de 2016. Disponível em: www.univali.br/direitoepolitica - ISSN 1980-7791.

"a justiça é, antes de tudo, uma característica possível, porém não necessária de uma ordem social" 39 .

A norma, portanto, não tem a pretensão de ser justa. Ela pode ou não ser justa, mas vai depender do intérprete, evidenciando a relatividade do conceito de Justiça no espaço e no tempo, pois não há um valor absoluto, e sim valores relativos; não há justiça absoluta, mas justiça relativa, ou seja, certos valores baseados no juízo de valor de alguém ou de um grupo não podem eliminar a possibilidade de valores assimétricos ou até opostos, pertencentes a outrem ou a um outro grupo. Ora, "isto significa dizer que a validade de uma ordem jurídica positiva é independente da sua concordância ou discordância com qualquer sistema moral" ${ }^{\prime 40}$.

Logo, fica evidenciado que uma moral relativa ou um parâmetro de justiça (também relativo) não podem fornecer uma medida ou padrão absoluto para valoração de uma ordem jurídica positiva.

Com efeito, "Kelsen não dá definição própria de Justiça e sustenta que a valoração ética do Direito não é função da Ciência Jurídica"41. Na verdade, Kelsen, em sua obra Teoria Pura do Direito, "postula o divórcio completo entre o mundo ser (sein) e o mundo do dever ser (sollen) ao declarar a total autonomia do Estado no processo da nomogênese e da coação"42.

Ainda sobre o assunto em comento, Kelsen disserta:

A justiça de um indivíduo é a justiça de sua conduta social; e a justiça da sua conduta social consiste em ela corresponder a uma norma que constitui o valor justiça e, neste sentido, ser justa. Podemos designar esta norma como norma da justiça. Como as normas da moral são normas sociais, isto

\footnotetext{
39 KELSEN, Hans. O que é Justiça?: a Justiça, o Direito e a Política no espelho da Ciência. $3^{a}$. ed. São Paulo: Martins Fontes, 2001, p. 1.

40 KELSEN, Hans. Teoria Pura do Direito. 6a. ed. São Paulo: Martins Fontes, 1998, p. 76.

41 PETRUCELI, Isabel Helena Andrade. Justiça, Validade e Eficácia das Normas Jurídicas - uma comparação entre a Teoria da Norma Jurídica de Norberto Bobbio e a Teoria Pura do Direito de Hans Kelsen. Revista E-Civitas, Uni-BH, Belo Horizonte, v. 1, n. 1, 2008.
}

42 CICCO, Claúdio de. História do Pensamento Jurídico e da Filosofia do Direito. 3a. ed. São Paulo: Saraiva, 2006, p. 298. 
SILVA, Lucas Antônio Lopes da; TEIXEIRA, Paulo Enderson de Oliveira; MENDES, Renat Nureyev. Por uma diferenciação dos critérios de justiça, validade e eficácia das normas jurídicas: Leitura comparativa das obras Teoria Pura do Direito, de Hans Kelsen e Teoria da Norma Jurídica, de Norberto Bobbio. Revista Eletrônica Direito e Política, Programa de Pós-Graduação Stricto Sensu em Ciência Jurídica da UNIVALI, Itajaí, v.11, n.2, 20 quadrimestre de 2016. Disponível em: www.univali.br/direitoepolitica - ISSN 1980-7791.

é, normas que regulam a conduta de indivíduos em face de outros indivíduos, a norma da justiça é uma norma moral; e, assim, também sob este aspecto conceito de justiça se enquadra no conceito da moral ${ }^{43}$.

Nesse diapasão, consoante o pensamento kelseniano, em função da íntima relação entre a justiça e a moral, o jurista deve se manter neutro, indiferente em relação ao conteúdo desta norma, já que esta é a sua função. "O jurista deve descrever o conteúdo da norma jurídica, e não discutir o valor de justiça em que ela se fundamentou, isto é, o jurista não deve introduzir elementos valorativos no seu discurso descritivo"44. A Ciência Jurídica também não tem que aprovar ou desaprovar o seu objeto, isto não cabe a ela; deveria apenas reconhecer e descrever, como já foi evidenciado. Seria uma descrição e reconhecimento alheios a valores. Nesse diapasão, "Kelsen reconhecia que não é possível nenhuma garantia de que uma determinada ordem jurídica possa ser considerada efetivamente justa em dado momento"45. Ademais, "não existe um elemento transcendental ou último que possa outorgar ao direito positivo o adjetivo de justo" ${ }^{\prime 46}$.

A justiça para Kelsen, portanto, "não deve ser discutida na Teoria Pura do Direito, cujo objetivo é única e exclusivamente o de conhecer o objeto do Direito não importando a questão de saber como deve ser o Direito, ou como ele deve ser feito"47. A Teoria do Direito é, em primeiro lugar, uma teoria, consoante o

43 Kelsen apud PETRUCELI, Isabel Helena Andrade. Justiça, Validade e Eficácia das Normas Jurídicas - uma comparação entre a Teoria da Norma Jurídica de Norberto Bobbio e a Teoria Pura do Direito de Hans Kelsen. Revista E-Civitas, Uni-BH, Belo Horizonte, v. 1, n. 1, 2008.

44 PETRUCELI, Isabel Helena Andrade. Justiça, Validade e Eficácia das Normas Jurídicas - uma comparação entre a Teoria da Norma Jurídica de Norberto Bobbio e a Teoria Pura do Direito de Hans Kelsen. Revista E-Civitas, Uni-BH, Belo Horizonte, v. 1, n. 1, 2008.

45 KOZICKI, Katya. Afinal, o que significa uma "Teoria do Direito"?. In: CERQUEIRA, Daniel Torres; FREGALE FILHO, Roberto. O Ensino Jurídico em Debate: o papel das disciplinas propedêuticas na formação jurídica. Campinas (SP): Millennium Editora, 2007, p. 16.

46 KOZICKI, Katya. Afinal, o que significa uma "Teoria do Direito"?. In: CERQUEIRA, Daniel Torres; FREGALE FILHO, Roberto. O Ensino Jurídico em Debate: o papel das disciplinas propedêuticas na formação jurídica. Campinas (SP): Millennium Editora, 2007, p. 16.

47 PETRUCELI, Isabel Helena Andrade. Justiça, Validade e Eficácia das Normas Jurídicas - uma comparação entre a Teoria da Norma Jurídica de Norberto Bobbio e a Teoria Pura do Direito de Hans Kelsen. Revista E-Civitas, Uni-BH, Belo Horizonte, v. 1, n. 1, 2008. 
SILVA, Lucas Antônio Lopes da; TEIXEIRA, Paulo Enderson de Oliveira; MENDES, Renat Nureyev. Por uma diferenciação dos critérios de justiça, validade e eficácia das normas jurídicas: Leitura comparativa das obras Teoria Pura do Direito, de Hans Kelsen e Teoria da Norma Jurídica, de Norberto Bobbio. Revista Eletrônica Direito e Política, Programa de Pós-Graduação Stricto Sensu em Ciência Jurídica da UNIVALI, Itajaí, v.11, n.2, $2^{\circ}$ quadrimestre de 2016. Disponível em: www.univali.br/direitoepolitica - ISSN 1980-7791.

pensamento kelseniano. "Seu objeto é responder à pergunta: 'que é o direito?' e não 'o que deve ser o direito'"'48.

O adjetivo "Pura" presente no título de sua obra, bem como de sua Teoria, propõe garantir um conhecimento apenas dirigido ao Direito em sua forma peculiar, "excluindo" deste, consequentemente, todo conhecimento que não pertença ao seu objeto, tudo que não possa, rigorosamente, ser determinado como Direito. Em suma, Kelsen quer "libertar a Ciência Jurídica de todos os elementos que Ihes são estranhos. Esse é o princípio metodológico fundamental"49.

Se propõe a produzir um conhecimento voltado exclusivamente ao Direito, apartando-o de tudo que não pertença ao mesmo, como a psicologia, sociologia, ética e teoria política, evitando um sincretismo metodológico que pudesse obscurecer a essência da ciência jurídica, apesar de reconhecer a conexão da mesma face das disciplinas ${ }^{50}$.

\subsection{VALIDADE E EFICÁCIA}

Kelsen, mesmo reconhecendo a dualidade de critérios nesse caso, vê uma íntima conexão entre a validade e a eficácia.

O critério da validade está relacionado à Norma Fundamental, pressuposto lógico, sem matéria, que estaria acima do ápice daquela clássica pirâmide kelseniana e daria, por conseguinte, validade a todas as normas, inclusive à Constituição. Isto é, "a norma fundamental seria a última e mais elevada das

\footnotetext{
48 MONTORO, André Franco. Introdução à Ciência do Direito. 29a ed. São Paulo: Editora Revista dos Tribunais, 2011, p. 302.

49 KELSEN, Hans. Teoria Pura do Direito. 6a. ed. São Paulo: Martins Fontes, 1998, p. 1.

50 MELLO, Pedro César Ivo Trindade. A relação entre Eficácia e Validade das Normas Jurídicas: diálogo entre as Teorias de Alf Ross e Hans Kelsen. In: Conpedi/Ufsc. (Org.). A relação entre Eficácia e Validade das Normas Jurídicas: diálogo entre as Teorias de Alf Ross e Hans Kelsen. 23ed. Florianópolis: Conpedi, 2014, v. T314, p. 413.
} 
SILVA, Lucas Antônio Lopes da; TEIXEIRA, Paulo Enderson de Oliveira; MENDES, Renat Nureyev. Por uma diferenciação dos critérios de justiça, validade e eficácia das normas jurídicas: Leitura comparativa das obras Teoria Pura do Direito, de Hans Kelsen e Teoria da Norma Jurídica, de Norberto Bobbio. Revista Eletrônica Direito e Política, Programa de Pós-Graduação Stricto Sensu em Ciência Jurídica da UNIVALI, Itajaí, v.11, n.2, 20 quadrimestre de 2016. Disponível em: www.univali.br/direitoepolitica - ISSN 1980-7791.

normas, ou seja, seria a fonte comum da validade de todas as normas pertencentes a uma mesma ordem jurídica"51.

Em outras palavras, a definição da norma fundamental "está intimamente ligada ao conceito de validade, pois o fundamento de validade de uma norma jurídica apenas pode decorrer da validade de uma outra norma jurídica, porque, para Kelsen, todas as normas necessitam de fundamento"52. É justamente nessa norma fundamental que poderá ser encontrado "o elemento de coesão e o fundamento último, e comum, de validade de todas as normas pertencentes a uma mesma ordem normativa, apesar deste fundamento último de validade não dispor a respeito do conteúdo da ordem dele derivada"53.

Destarte, para averiguar se uma norma é válida, ter-se-ia que verificar se a mesma está de acordo com a norma imediatamente superior naquela hierarquia do ordenamento jurídico (pirâmide kelseniana), e ir subindo até a Norma Fundamental. Dito de uma outra forma, "o fundamento de validade de uma norma pertencente a uma determinada ordem jurídica está relacionado a se essa norma foi produzida de acordo com a norma fundamental"54. Em vista disso,

Na concepção kelseniana, a validade de uma norma apenas pode ser buscada em outra, considerada como hierarquicamente superior. Para que a norma seja reputada como existente ela precisa, necessariamente, cumprir com os requisitos de validade postos pelo próprio ordenamento, sem precisar buscar lastro em qualquer circunstância empírica ou matajurídica. Assim, as normas perfazem um

51 PETRUCELI, Isabel Helena Andrade. Justiça, Validade e Eficácia das Normas Jurídicas - uma comparação entre a Teoria da Norma Jurídica de Norberto Bobbio e a Teoria Pura do Direito de Hans Kelsen. Revista E-Civitas, Uni-BH, Belo Horizonte, v. 1, n. 1, 2008.

52 PETRUCELI, Isabel Helena Andrade. Justiça, Validade e Eficácia das Normas Jurídicas - uma comparação entre a Teoria da Norma Jurídica de Norberto Bobbio e a Teoria Pura do Direito de Hans Kelsen. Revista E-Civitas, Uni-BH, Belo Horizonte, v. 1, n. 1, 2008.

53 MELLO, Pedro César Ivo Trindade. A relação entre Eficácia e Validade das Normas Jurídicas: diálogo entre as Teorias de Alf Ross e Hans Kelsen. In: Conpedi/Ufsc. (Org.). A relação entre Eficácia e Validade das Normas Jurídicas: diálogo entre as Teorias de Alf Ross e Hans Kelsen. 23ed. Florianópolis: Conpedi, 2014, v. T314, p. 415.

54 PETRUCELI, Isabel Helena Andrade. Justiça, Validade e Eficácia das Normas Jurídicas - uma comparação entre a Teoria da Norma Jurídica de Norberto Bobbio e a Teoria Pura do Direito de Hans Kelsen. Revista E-Civitas, Uni-BH, Belo Horizonte, v. 1, n. 1, 2008. 
SILVA, Lucas Antônio Lopes da; TEIXEIRA, Paulo Enderson de Oliveira; MENDES, Renat Nureyev. Por uma diferenciação dos critérios de justiça, validade e eficácia das normas jurídicas: Leitura comparativa das obras Teoria Pura do Direito, de Hans Kelsen e Teoria da Norma Jurídica, de Norberto Bobbio. Revista Eletrônica Direito e Política, Programa de Pós-Graduação Stricto Sensu em Ciência Jurídica da UNIVALI, Itajaí, v.11, n.2, 20 quadrimestre de 2016. Disponível em: www.univali.br/direitoepolitica - ISSN 1980-7791.

sistema que encontra fundamento comum de validade na denominada norma fundamental (grundnorm) ${ }^{55}$.

Em síntese, "para estabelecer a validade das regras de direito e das instituições jurídicas, Kelsen afasta qualquer preocupação com sua justiça ou valor. Não Ihe interessa o conteúdo das normas. Mas apenas seu aspecto 'formal' de subordinação à regra fundamental"56.

Já a eficácia em Kelsen teria a semântica similar à eficácia em Bobbio, visto que ambas se referem ao respeito da norma jurídica pelos seus destinatários, ou seja, se a norma jurídica está sendo ou não seguida por aqueles a quem ela se dirige. Ela está relacionada, nesse ínterim, "à aplicação e à observação da norma, isto é, concerne à condição de existência no mundo do ser e não ao fundamento de validade da norma, enquanto dever-ser"57.

As normas jurídicas "não são geradas por acaso, mas visando a alcançar certos resultados sociais. Como processo de adaptação social que é, o Direito se apresenta como fórmula capaz de resolver problemas de convivência e de organização social"58. Ou seja, "o atributo eficácia significa que a norma jurídica produz, realmente, os efeitos sociais planejados. Para que a eficácia se manifeste, indispensável é que seja observada socialmente. Eficácia pressupõe, destarte, efetividade"

O relacionamento entre eficácia e a validade, no que se refere às normas, "pode ser encontrado na medida em que Kelsen reputa que, em regra, o

55 MELLO, Pedro César Ivo Trindade. A relação entre Eficácia e Validade das Normas Jurídicas: diálogo entre as Teorias de Alf Ross e Hans Kelsen. In: Conpedi/Ufsc. (Org.). A relação entre Eficácia e Validade das Normas Jurídicas: diálogo entre as Teorias de Alf Ross e Hans Kelsen. 23ed. Florianópolis: Conpedi, 2014, v. T314, p. 412.

56 MONTORO, André Franco. Introdução à Ciência do Direito. 29a ed. São Paulo: Editora Revista dos Tribunais, 2011 , p. 302.

57 PETRUCELI, Isabel Helena Andrade. Justiça, Validade e Eficácia das Normas Jurídicas - uma comparação entre a Teoria da Norma Jurídica de Norberto Bobbio e a Teoria Pura do Direito de Hans Kelsen. Revista E-Civitas, Uni-BH, Belo Horizonte, v. 1, n. 1, 2008.

58 NADER, Paulo. Introdução ao Estudo do Direito. 34a. ed. Rio de Janeiro: Forense, 2012 , p. 17.

59 NADER, Paulo. Introdução ao Estudo do Direito. 34a. ed. Rio de Janeiro: Forense, 2012, p. 17. 
SILVA, Lucas Antônio Lopes da; TEIXEIRA, Paulo Enderson de Oliveira; MENDES, Renat Nureyev. Por uma diferenciação dos critérios de justiça, validade e eficácia das normas jurídicas: Leitura comparativa das obras Teoria Pura do Direito, de Hans Kelsen e Teoria da Norma Jurídica, de Norberto Bobbio. Revista Eletrônica Direito e Política, Programa de Pós-Graduação Stricto Sensu em Ciência Jurídica da UNIVALI, Itajaí, v.11, n.2, 20 quadrimestre de 2016. Disponível em: www.univali.br/direitoepolitica - ISSN 1980-7791.

descumprimento da norma não tem o condão de invalidá-la. Em verdade, a prática de um ato ilícito é o pressuposto para que haja a aplicação do direito pelos tribunais" ${ }^{60}$.

Nesse diapasão, a regra é a de que a eficácia da norma, "que pode ser evidenciada na modalidade observância por parte dos jurisdicionados ou aplicação pelas autoridades competentes, não opera efeitos concernentes à validade, exceto na hipótese dela ser duradouramente ineficaz"61. Com efeito, "o campo da validade das normas é a obrigação, isto é, as normas devem ser obedecidas pelos homens, ao passo que a eficácia é de certa forma um atributo secundário, ou seja, fica no campo da sua aplicação e do seu cumprimento" ${ }^{62}$.

De outro lado, "há acentuadas críticas à grundnorm, uma vez que, ao adotá-la, Kelsen indiretamente imputou a eficácia como algo elementar à validade do ordenamento jurídico como um todo"63.

Observa-se, desta maneira, que, por um lado, Kelsen separa validade e eficácia, e, por outro, as identifica.

[Ele] sublinha a desvinculação existente entre as esferas da validade e da

60 MELLO, Pedro César Ivo Trindade. A relação entre Eficácia e Validade das Normas Jurídicas: diálogo entre as Teorias de Alf Ross e Hans Kelsen. In: Conpedi/Ufsc. (Org.). A relação entre Eficácia e Validade das Normas Jurídicas: diálogo entre as Teorias de Alf Ross e Hans Kelsen. 23ed. Florianópolis: Conpedi, 2014, v. T314, p. 412.

61 MELLO, Pedro César Ivo Trindade. A relação entre Eficácia e Validade das Normas Jurídicas: diálogo entre as Teorias de Alf Ross e Hans Kelsen. In: Conpedi/Ufsc. (Org.). A relação entre Eficácia e Validade das Normas Jurídicas: diálogo entre as Teorias de Alf Ross e Hans Kelsen. 23ed. Florianópolis: Conpedi, 2014, v. T314, p. 412.

62 EBAID, Ana Augusta Rodrigues Westin. O Confronto das Teorias de Hans Kelsen e Robert Alexy: entre o Normativismo e a Dimensão pós-positivista. In: Colloquium Humanarum, vol. 10, $\mathrm{n}$. Especial, jul./dez., 2013, p. 97.

63 MELLO, Pedro César Ivo Trindade. A relação entre Eficácia e Validade das Normas Jurídicas: diálogo entre as Teorias de Alf Ross e Hans Kelsen. In: Conpedi/Ufsc. (Org.). A relação entre Eficácia e Validade das Normas Jurídicas: diálogo entre as Teorias de Alf Ross e Hans Kelsen. 23ed. Florianópolis: Conpedi, 2014, v. T314, p. 412. 
SILVA, Lucas Antônio Lopes da; TEIXEIRA, Paulo Enderson de Oliveira; MENDES, Renat Nureyev. Por uma diferenciação dos critérios de justiça, validade e eficácia das normas jurídicas: Leitura comparativa das obras Teoria Pura do Direito, de Hans Kelsen e Teoria da Norma Jurídica, de Norberto Bobbio. Revista Eletrônica Direito e Política, Programa de Pós-Graduação Stricto Sensu em Ciência Jurídica da UNIVALI, Itajaí, v.11, n.2, $2^{\circ}$ quadrimestre de 2016. Disponível em: www.univali.br/direitoepolitica - ISSN 1980-7791.

eficácia, aquela de natureza formal, lógica, e esta material, sociológica. Para ser válida, a norma jurídica não precisa ser eficaz. Contudo, um mínimo de eficácia é condição de validade, visto que a norma jurídica válida pode perder tal atributo ao longo do tempo em razão do desuso. Mas o mínimo de eficácia não é pressuposto da validade, papel reservado exclusivamente à norma fundamental 64 .

Mesmo separando os critérios, Kelsen notou que, "sem um mínimo de eficácia a norma não poderia ser válida. Isto é, a norma teria de ter as condições mínimas para que a conduta regulada pudesse ocorrer ou não no plano dos fatos, para alcançar validade"65.

\section{CONSIDERAÇÕES FINAIS}

Ao longo deste trabalho buscou-se compreender como foram lidos os critérios de Justiça, Validade e Eficácia nos pensamentos de Hans Kelsen e Norberto Bobbio, principalmente nas obras Teoria da Norma Jurídica e Teoria Pura do Direito, entre outras.

Observou-se aqui que os critérios em comento são demasiadamente próximos uns dos outros, com uma linha tênue que os separa. No entanto, cada um deles, como foi visto, guarda suas particularidades, mesmo Kelsen "condicionando" a validade a um mínimo de eficácia, ele parece optar pela independência dos critérios, assim como o fez, de maneira muito mais explícita, Bobbio, que também advogou pela autonomia dos critérios (mesmo reconhecendo a interligação evidente dos mesmos).

\footnotetext{
64 MATOS, Andityas Soares de Moura Costa. A Norma Fundamental de Hans Kelsen como postulado científico. In: Revista da Faculdade de Direito da UFMG, Belo Horizonte, n. 58, jan./jun., 2011 , p. 49.

65 DANTAS, Marcelo Navarro Ribeiro. Existência, Vigência, Validade, Eficácia e Efetividade das Normas Jurídicas. In: Revista Ciência Jurídica, ano VII, v. 49, jan./fev., 1993, pp. 32-33.
} 
SILVA, Lucas Antônio Lopes da; TEIXEIRA, Paulo Enderson de Oliveira; MENDES, Renat Nureyev. Por uma diferenciação dos critérios de justiça, validade e eficácia das normas jurídicas: Leitura comparativa das obras Teoria Pura do Direito, de Hans Kelsen e Teoria da Norma Jurídica, de Norberto Bobbio. Revista Eletrônica Direito e Política, Programa de Pós-Graduação Stricto Sensu em Ciência Jurídica da UNIVALI, Itajaí, v.11, n.2, 20 quadrimestre de 2016. Disponível em: www.univali.br/direitoepolitica - ISSN 1980-7791.

Concluiu-se, portanto, que, também pelo fato de serem ambos Juspositivistas, os dois autores têm alguns aspectos em comum em suas doutrinas, no que se referem aos critérios da Justiça, Validade e Eficácia. Todavia, divergem em alguns outros pontos.

Bobbio e Kelsen concordam que a Justiça seja de âmbito subjetivo; no tocante à Validade, Bobbio propõe impõe três condições para sua verificação, enquanto Kelsen à relaciona diretamente com a norma fundamental; e, finalmente, acerca da Eficácia, os dois autores em tela concordam que esta está muito próxima à Validade, porém uma não deve ser confundida com a outra66.

Para um melhor esclarecimento do que foi tratado neste estudo, optou-se em reproduzir o quadro comparativo do artigo de Petruceli67. Este ajudará o leitor a visualizar mais nitidamente o que foi trabalhado até aqui.

66 PETRUCELI, Isabel Helena Andrade. Justiça, Validade e Eficácia das Normas Jurídicas - uma comparação entre a Teoria da Norma Jurídica de Norberto Bobbio e a Teoria Pura do Direito de Hans Kelsen. Revista E-Civitas, Uni-BH, Belo Horizonte, v. 1, n. 1, 2008.

67 PETRUCELI, Isabel Helena Andrade. Justiça, Validade e Eficácia das Normas Jurídicas - uma comparação entre a Teoria da Norma Jurídica de Norberto Bobbio e a Teoria Pura do Direito de Hans Kelsen. Revista E-Civitas, Uni-BH, Belo Horizonte, v. 1, n. 1, 2008. 
SILVA, Lucas Antônio Lopes da; TEIXEIRA, Paulo Enderson de Oliveira; MENDES, Renat Nureyev. Por uma diferenciação dos critérios de justiça, validade e eficácia das normas jurídicas: Leitura comparativa das obras Teoria Pura do Direito, de Hans Kelsen e Teoria da Norma Jurídica, de Norberto Bobbio. Revista Eletrônica Direito e Política, Programa de Pós-Graduação Stricto Sensu em Ciência Jurídica da UNIVALI, Itajaí, v.11, n.2, 20 quadrimestre de 2016. Disponível em: www.univali.br/direitoepolitica - ISSN 1980-7791.

\section{QUADRO COMPARATIVO}

\begin{tabular}{|c|c|c|}
\hline CRITÉRIOS & NORBERTO BOBBIO & HANS KELSEN \\
\hline Justiça & $\begin{array}{l}\text { É a dicotomia entre o } \\
\text { mundo ideal e o mundo } \\
\text { real. Norma Justa é } \\
\text { aquela que deve ser e } \\
\text { injusta aquela que não } \\
\text { deveria ser. }\end{array}$ & $\begin{array}{l}\text { Não deve ser discutida } \\
\text { na Teoria Pura do } \\
\text { Direito, cujo objetivo é } \\
\text { única e exclusivamente } \\
\text { o de conhecer o objeto } \\
\text { do Direito, não } \\
\text { importando a questão } \\
\text { de saber como deve ser } \\
\text { o Direito. }\end{array}$ \\
\hline Validade & $\begin{array}{l}\text { É necessário realizar } \\
\text { três operação: I) } \\
\text { Averiguar se a } \\
\text { autoridade de quem } \\
\text { emanou tinha o poder } \\
\text { legítimo para produzir } \\
\text { normas jurídicas; II) } \\
\text { Comprovar se não foi } \\
\text { ab-rogada; } \text { III) } \\
\text { Verificar se não é } \\
\text { incompatível com } \\
\text { outras normas do } \\
\text { sistema também } \\
\text { particularmente com } \\
\text { uma norma } \\
\text { hierarquicamente } \\
\text { superior. }\end{array}$ & $\begin{array}{l}\text { Observar se a } \\
\text { foi produzida de } \\
\text { com acordo } \\
\text { fundamental. }\end{array}$ \\
\hline Eficácia & $\begin{array}{l}\text { Está relacionada ao } \\
\text { problema de uma }\end{array}$ & $\begin{array}{lcc}\text { Está } & \text { relacionada } & \text { à } \\
\text { aplicação } & \text { e } & \text { à }\end{array}$ \\
\hline
\end{tabular}


SILVA, Lucas Antônio Lopes da; TEIXEIRA, Paulo Enderson de Oliveira; MENDES, Renat Nureyev. Por uma diferenciação dos critérios de justiça, validade e eficácia das normas jurídicas: Leitura comparativa das obras Teoria Pura do Direito, de Hans Kelsen e Teoria da Norma Jurídica, de Norberto Bobbio. Revista Eletrônica Direito e Política, Programa de Pós-Graduação Stricto Sensu em Ciência Jurídica da UNIVALI, Itajaí, v.11, n.2, $2^{\circ}$ quadrimestre de 2016. Disponível em: www.univali.br/direitoepolitica - ISSN 1980-7791.

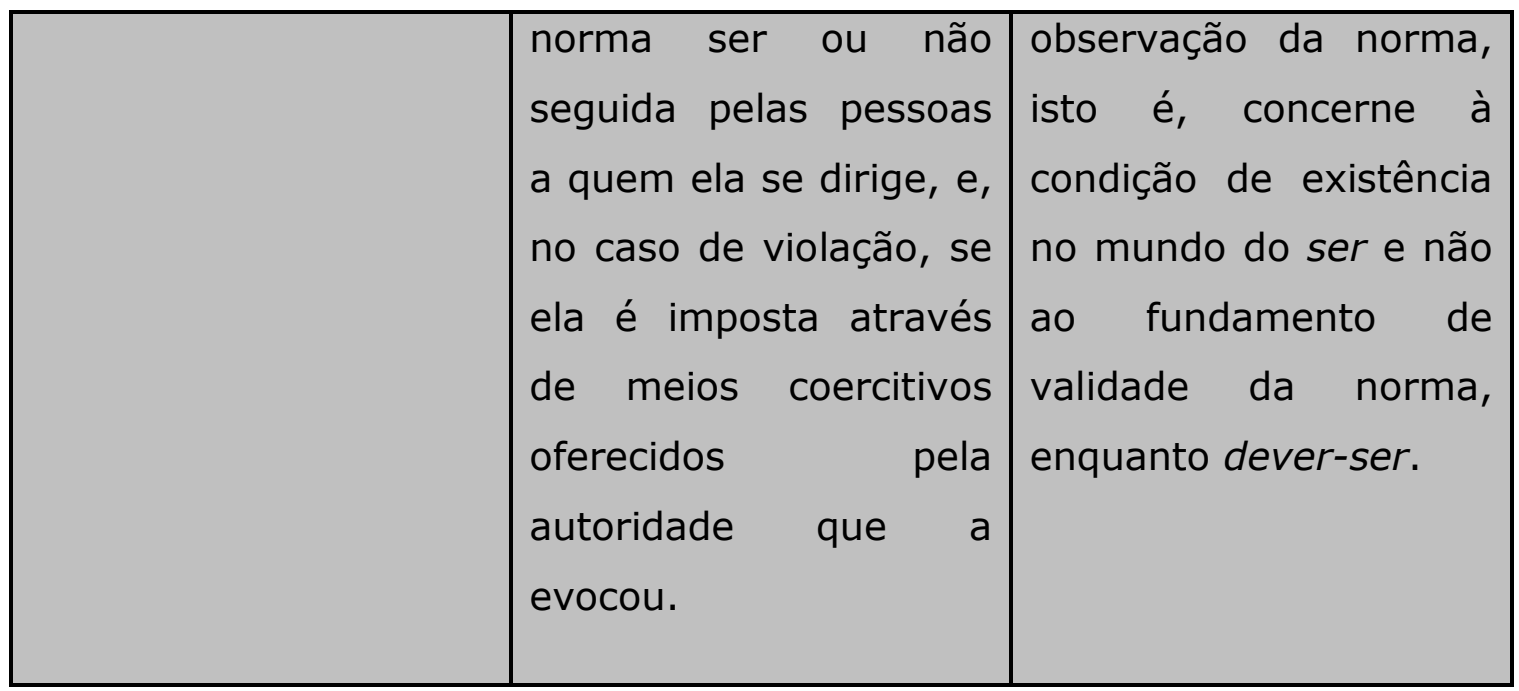

In: PETRUCELI, Isabel Helena Andrade. Justiça, Validade e Eficácia das Normas Jurídicas uma comparação entre a Teoria da Norma Jurídica de Norberto Bobbio e a Teoria Pura do Direito de Hans Kelsen. Revista E-Civitas, Uni-BH, Belo Horizonte, v. 1, n. 1, 2008.

\section{REFERÊNCIAS DAS FONTES CITADAS}

BAGGENSTOSS, Grazielly Alessandra. A contemporaneidade das teorias reducionistas a partir da teoria jurídica bobbiana. In: Revista de Estudos Constitucionais, Hermenêutica e Teoria do Direito (RECHTD), v. 6, n. 2, julho-setembro, 2014, pp. 167-175.

BOBBIO, Norberto. Teoria da Norma Jurídica. Bauru (SP): EDIPRO, 2001.

BOBBIO, Norberto. Teoria do Ordenamento Jurídico. Brasília: Editora UnB, 1999.

CICCO, Claúdio de. História do Pensamento Jurídico e da Filosofia do Direito. 3a. ed. São Paulo: Saraiva, 2006.

DANTAS, Marcelo Navarro Ribeiro. Existência, Vigência, Validade, Eficácia e Efetividade das Normas Jurídicas. In: Revista Ciência Jurídica, ano VII, v. 49, jan./fev., 1993, pp. 27-46. 
SILVA, Lucas Antônio Lopes da; TEIXEIRA, Paulo Enderson de Oliveira; MENDES, Renat Nureyev. Por uma diferenciação dos critérios de justiça, validade e eficácia das normas jurídicas: Leitura comparativa das obras Teoria Pura do Direito, de Hans Kelsen e Teoria da Norma Jurídica, de Norberto Bobbio. Revista Eletrônica Direito e Política, Programa de Pós-Graduação Stricto Sensu em Ciência Jurídica da UNIVALI, Itajaí, v.11, n.2, $2^{\circ}$ quadrimestre de 2016. Disponível em: www.univali.br/direitoepolitica - ISSN 1980-7791.

EBAID, Ana Augusta Rodrigues Westin. O Confronto das Teorias de Hans Kelsen e Robert Alexy: entre o Normativismo e a Dimensão pós-positivista. In: Colloquium Humanarum, vol. 10, n. Especial, jul./dez., 2013, pp. 95-100.

KELSEN, Hans. O problema da Justiça. 3a. ed. São Paulo: Martins Fontes, 1988.

KELSEN, Hans. O que é Justiça?: a Justiça, o Direito e a Política no espelho da Ciência. 3a. ed. São Paulo: Martins Fontes, 2001.

KELSEN, Hans. Teoria Pura do Direito. 6a. ed. São Paulo: Martins Fontes, 1998.

KOZICKI, Katya. Afinal, o que significa uma "Teoria do Direito"?. In: CERQUEIRA, Daniel Torres; FREGALE FILHO, Roberto. O Ensino Jurídico em Debate: o papel das disciplinas propedêuticas na formação jurídica. Campinas (SP): Millennium Editora, 2007.

LOURINHO, Sergio Manuel. Norberto Bobbio e uma Teoria Geral do Direito. In: Revista Jurídica das Faculdades Secal, Ponta Grossa, v. 1, n. 1, jan./jun., 2011, pp. 96-118.

MATOS, Andityas Soares de Moura Costa. A Norma Fundamental de Hans Kelsen como postulado científico. In: Revista da Faculdade de Direito da UFMG, Belo Horizonte, n. 58, jan./jun., 2011, pp. 41-84.

MELLO, Pedro César Ivo Trindade. A relação entre Eficácia e Validade das Normas Jurídicas: diálogo entre as Teorias de Alf Ross e Hans Kelsen. In: Conpedi/Ufsc. (Org.). A relação entre Eficácia e Validade das Normas Jurídicas: diálogo entre as Teorias de Alf Ross e Hans Kelsen. 23ed. Florianópolis: Conpedi, 2014, v. T314, p. 411-433.

MENDONÇA, Jacy de Souza. Introdução ao Estudo do Direito. 3a. ed. São Paulo: Rideel, 2010.

MONTORO, André Franco. Introdução à Ciência do Direito. 29a ed. São Paulo: Editora Revista dos Tribunais, 2011. 
SILVA, Lucas Antônio Lopes da; TEIXEIRA, Paulo Enderson de Oliveira; MENDES, Renat Nureyev. Por uma diferenciação dos critérios de justiça, validade e eficácia das normas jurídicas: Leitura comparativa das obras Teoria Pura do Direito, de Hans Kelsen e Teoria da Norma Jurídica, de Norberto Bobbio. Revista Eletrônica Direito e Política, Programa de Pós-Graduação Stricto Sensu em Ciência Jurídica da UNIVALI, Itajaí, v.11, n.2, 20 quadrimestre de 2016. Disponível em: www.univali.br/direitoepolitica - ISSN 1980-7791.

NADER, Paulo. Introdução ao Estudo do Direito. 34a. ed. Rio de Janeiro: Forense, 2012.

PETRUCELI, Isabel Helena Andrade. Justiça, Validade e Eficácia das Normas Jurídicas - uma comparação entre a Teoria da Norma Jurídica de Norberto Bobbio e a Teoria Pura do Direito de Hans Kelsen. In: Revista E-Civitas, Uni$\mathrm{BH}$, Belo Horizonte, v. 1, n. 1, 2008.

QUEIRÓZ, Daniela Costa. A Crise do JusPositivismo. In: Lumiar - Revista de Ciências Jurídicas, Ponta Grossa, v. 3, n. 1, 2011, pp. 39-45.

Submetido em: Novembro/2015

Aprovado em: Abril/2016 